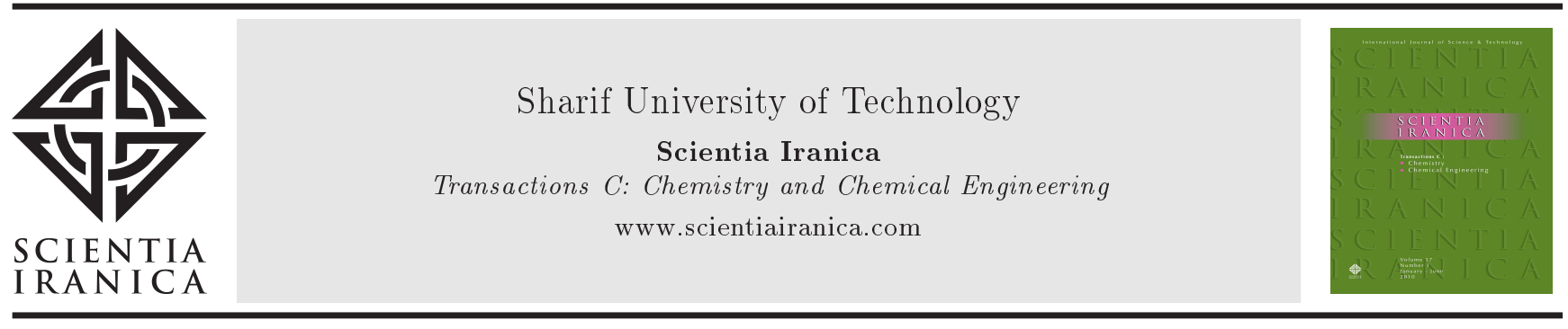

\title{
Separation of helium from gases using the synthesized hydroxy sodalite membrane
}

\author{
M.J. Vaezi $i^{a, b}$, Y. Bayat ${ }^{a, b}$, A.A. Babaluo ${ }^{a, b, *}$ and S. Shafiei ${ }^{b}$ \\ a. Nanostructure Material Research Center (NMRC), Sahand University of Technology, Tabriz, P.O. Box 51335-1996, Iran. \\ b. Department of Chemical Engineering, Sahand University of Technology, Tabriz, P.O. Box 51335-1996, Iran.
}

Received 26 January 2015; received in revised form 16 June 2015; accepted 21 November 2015

\section{KEYWORDS \\ Helium separation; Inorganic membrane; Hydroxy sodalite; Gas permeation; High temperatures.}

\begin{abstract}
The goals of this work are to synthesize and evaluate the potential of hydroxy sodalite membrane in the separation of helium from natural gas. Sodalite membrane was synthesized via direct hydrothermal method (conventional heating) on tubular alumina support. It was characterized by X-Ray Diffraction (XRD), Scanning Electron Microscopy (SEM), and single gas permeation using helium and $\mathrm{N}_{2}$. After drying the membrane, permeances of the single gases were found to be of the order helium $>\mathrm{CH}_{4}>\mathrm{N}_{2}>\mathrm{CO}_{2}$ at low temperatures and the membrane was impermeable to $\mathrm{N}_{2}, \mathrm{CO}_{2}$, and $\mathrm{CH}_{4}$ at high temperatures $\left(>85^{\circ} \mathrm{C}\right)$. In the investigated range of temperature $35-180^{\circ} \mathrm{C}$, membrane performance tended to high selectivity. The maximum separation factors (helium $/ \mathrm{N}_{2} \sim$ 8.8, helium $/ \mathrm{CO}_{2} \sim 16.5$ and helium $/ \mathrm{CH}_{4} \sim 5$ ) with acceptable permeance were observed at $85^{\circ} \mathrm{C}$.

(C) 2016 Sharif University of Technology. All rights reserved.
\end{abstract}

\section{Introduction}

In recent years, helium has been used increasingly in medical and critical productions - in Magnetic Resonance Imaging (MRI), production of pure liquid hydrogen in $-270^{\circ} \mathrm{C}$, cleaning the hydrogen and helium to remove admixtures, and using as inert gas in some dangerous applications [1-3]. These demands for helium in gaseous and liquid forms are grown rapidly. However, the high cost of its production has held back the needs for helium, since there are no natural highconcentration sources and it is limited to a few natural gas fields which have enough concentration of helium for economical separation [4]. So, the production methods of helium have achieved commercial importance. The most popular approach to helium production is cryogenic process, where helium is obtained from the helium-hydrogen mixture in cryogenic distillation [5].

*. Corresponding author. Tel.: +98 4133458084 ;

Fax: +984133458084

E-mail address: a.babaluo@sut.ac.ir (A.A. Babaluo)
But, the difficult operation and high energy cost of this process cause a technological and energetic challenge according to its important application in production and storage of helium. So, at the present time, it is very well-timed to study the ability of membrane process as a new technology which has efficient role in decreasing cost of helium purification due to not involving phase change [5-7].

Several efforts have been made, up to now, by different groups in developing helium purification by organic membranes [8-13]. Peterson and Stone [14] used phosphazene polymer membranes, where transport of helium and $\mathrm{CH}_{4}$ was found to be permeability size controlled process. Agrawal and Sourirajan [15] used cellulose acetate membrane at high pressures and reported the selectivity of 1.78 and 2.83 for helium $/ \mathrm{CH}_{4}$ and helium $/ \mathrm{N}_{2}$, respectively. But in general, organic membranes are not stable at temperatures higher than $100^{\circ} \mathrm{C}[16,17]$. So, some kinds of inorganic membrane were developed instead of polymeric membrane for separation of helium from natural gas. Arkharov et al. chose silica glass as a membrane 
material, which had high selectivity for passing helium compared to neon [18]. Favvas et al. studied the performance of carbon hollow fiber membrane at different temperatures and found the selectivity of 843 at $373 \mathrm{~K}$ for $\mathrm{H}_{2} / \mathrm{CH}_{4}$ [19]. Just recently, Favvas et al. investigated the effect of pyrolysis isothermal time on the separation of helium and $\mathrm{H}_{2}$ with carbon hollow fiber membrane and found the selectivity of 2945 and 350 for helium $/ \mathrm{CH}_{4}$ and helium $/ \mathrm{N}_{2}$, respectively [20]. Kafrouni et al. synthesized a-SiCXNY:H membrane in which ideal helium/ $\mathrm{N}_{2}$ selectivity of 50 was achieved at $150^{\circ} \mathrm{C}$ with a helium permeance of about $10^{-7}$ mol.m ${ }^{-2} \cdot \mathrm{Pa}^{-1} \cdot \mathrm{s}^{-1}$ [21]. Schrier studied the permeability of synthesized porous graphene and showed that the large differences in the needed energy for diffusing helium and $\mathrm{CH}_{4}$ through this membrane allow for highly selective separation of helium from natural gas [22]. Recently, $\mathrm{Li}$ et al. investigated the graphene oxide membrane for hydrogen separation. This membrane has excellent separation performance for $\mathrm{H}_{2} / \mathrm{CO}_{2}$ and $\mathrm{H}_{2} / \mathrm{N}_{2}$ (selectivity 3400 and 900, respectively) [23]. But, preparation of these membranes is very difficult. In contrast to these membranes, zeolite membranes have routine and repetitive synthesis method. So, this feature, together with well-defined intra-crystalline pores, and superior properties of zeolite membrane have attracted considerable attentions for gas separation processes [24-27].

Among the zeolites, hydroxy sodalite zeolite membrane with a three-dimensional channel network and a pore size of $2.8 \AA$ has high potential for separation of small molecules such as $\mathrm{NH}_{3}(2.55 \AA)$, helium $(2.6 \AA)$, and $\mathrm{H}_{2} \mathrm{O}(2.7 \AA)$ from gas mixtures [28,29]. But, few works have been presented on the separation of helium and hydrogen from natural gas using sodalite membrane; so, research on the evaluation of the performance of this membrane in the separation of helium $/ \mathrm{CH}_{4}$ gas mixture is needed.

The main objective of this study was to synthesize inorganic hydroxy sodalite membrane on the outer surface of homemade macroporous tubular ceramic support via hydrothermal method. The prepared membrane morphology and crystallinity were characterized by SEM and XRD analyses, respectively. The single gas permeation of helium, $\mathrm{N}_{2}, \mathrm{CH}_{4}$, and $\mathrm{CO}_{2}$ is carried out as a function of temperature and mean pressure. Performance of the prepared membrane was investigated at high temperatures to obtain high permselective behavior.

\section{Experimental}

\subsection{Material and methods}

A homemade tubular $\alpha$-alumina support was prepared by gel casting method (6 $\mathrm{mm}$ inner diameter, $12 \mathrm{~mm}$ outer diameter, $3 \mathrm{~mm}$ in thickness) with an average pore size of $570 \mathrm{~nm}$ and porosity of $42-47 \%$. The supports were prepared following a procedure described in the literature [30]. The synthesis solution of sodalite membrane was prepared by mixing the two appropriate precursor solutions named aluminate and silicate. The aluminate solution was prepared by dissolving amounts of deionized water $(25 \mathrm{ml})$, sodium hydroxide $(5.72 \mathrm{~g}$, $\mathrm{NaOH}$, Merck, > 99\%), and pure aluminum (0.14 g, $\mathrm{Al}$, Merck, > 99\%). The silicate solution was made by mixing amounts of deionized water $(22.7 \mathrm{ml})$, sodium hydroxide $(4.87 \mathrm{~g})$, and silica sol $(2.75 \mathrm{ml}$, [SiOx $(\mathrm{OH}) 4-$ $2 \mathrm{x}] \mathrm{n}$, Merk, 27 wt. $\left.\% \mathrm{SiO}_{2}\right)$. Then, the prepared solutions were heated at $50^{\circ} \mathrm{C}$ for 15 min and mixed to obtain a uniform clear solution. The molar ratio of the prepared solution was $5 \mathrm{SiO}_{2}: \mathrm{Al}_{2} \mathrm{O}_{3}: 50 \mathrm{Na}_{2} \mathrm{O}: 1000 \mathrm{H}_{2} \mathrm{O}$. The final solution was poured into the autoclave. In order to synthesize a zeolite layer on the outer surface of the support, two ends of the support were closed by Teflon. The synthesis was carried out at $90^{\circ} \mathrm{C}$ for $12 \mathrm{~h}$. The synthesized membrane was washed with deionized water until $\mathrm{pH}$ of the washing water decreased to neutral, after which the membranes were dried at $150^{\circ} \mathrm{C}$ for $3 \mathrm{~h}$ for removal of water molecules.

\subsection{Characterization}

The crystallite size and zeolite phase crystallinity of the synthesized sodalite zeolite membrane were found by XRD patterns. XRD analysis was carried out on a Bruker D8 ADVANCE X'Pert diffractometer using $\mathrm{CuKa}(l=1.54 \AA)$ radiation operating at $40 \mathrm{kV}$ and $40 \mathrm{~mA}$ (step size $=0.05\left[^{\circ} 2 \mathrm{Th}\right]$ ). The morphology and thickness of the synthesized membrane were observed by SEM analysis. Gas permeation experiments (helium and $\mathrm{N}_{2}$ ) were carried out as the best method to describe the quality of membrane. Because, when the hydroxy sodalite pores are blocked with the water molecules, no other molecule can diffuse through the membrane unless through defects. After membrane quality test, the synthesized membrane was dried at $150^{\circ} \mathrm{C}$ for $3 \mathrm{~h}$ to dehydrate the sodalite pores $[27,31,32]$. The membrane was placed inside a stainless steel permeation cell and sealed with O-rings and, finally, it was placed in oven with digital temperature controller. The membrane module is shown in Figure 1, schematically. Single gas permeation was measured by a soap-film flow meter at different temperatures under different pressures in a homemade set up (Figure 2). The perm-selectivity of helium to other gases was defined as the permeance ratio of helium to the related gases $\left(\mathrm{N}_{2}, \mathrm{CO}_{2}\right.$ and $\left.\mathrm{CH}_{4}\right)$.

\section{Results and discussion}

\subsection{Morphology and crystallinity}

The synthesized membrane was characterized by XRD and SEM analyses. The XRD pattern was made using a piece of sample that was synthesized at the same 


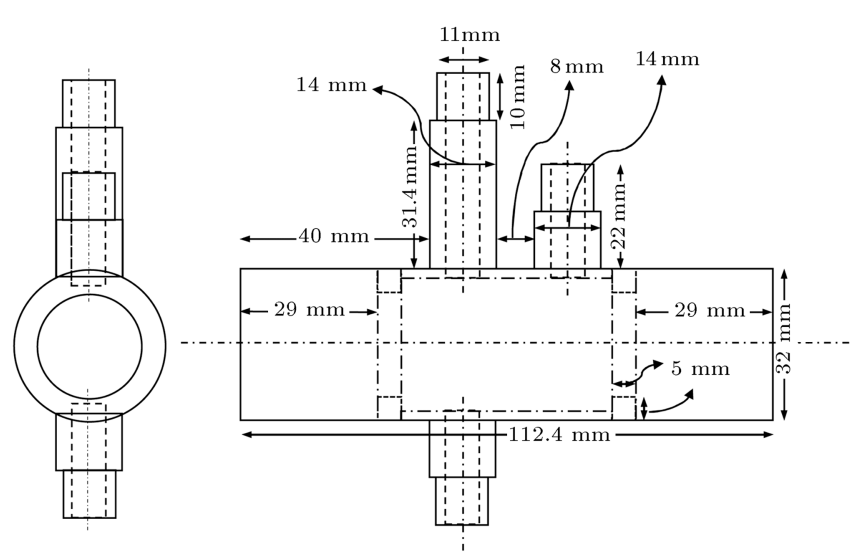

(1)
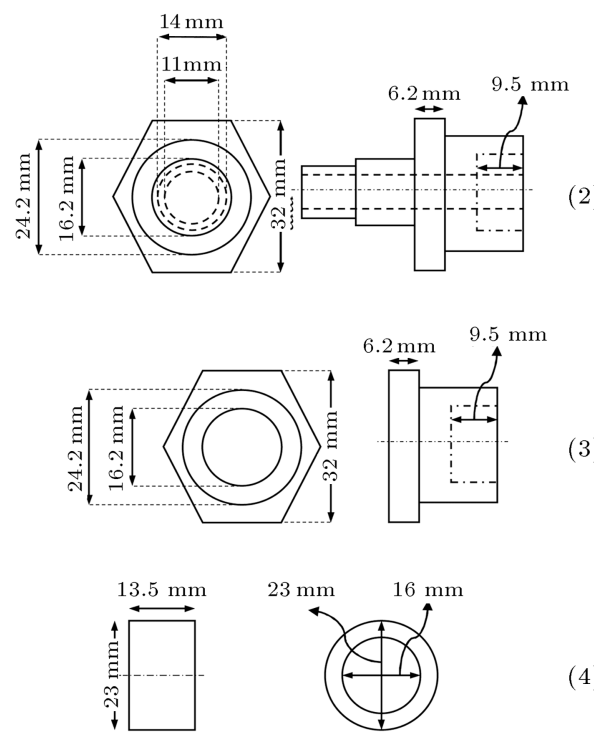

(4)

Figure 1. Diagram of the tested membrane module: (1) The main body of module; (2) cap with aperture for permeate; (3) cap for the other side of module; and (4) brazen ring for both sides.

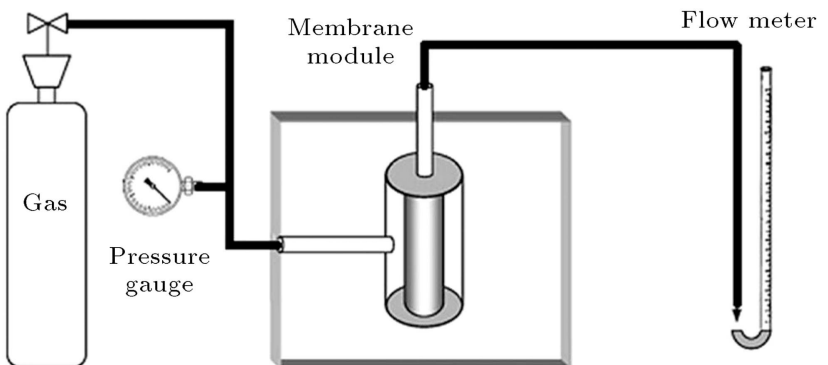

Figure 2. Experimental homemade set-up for single gas permeation.

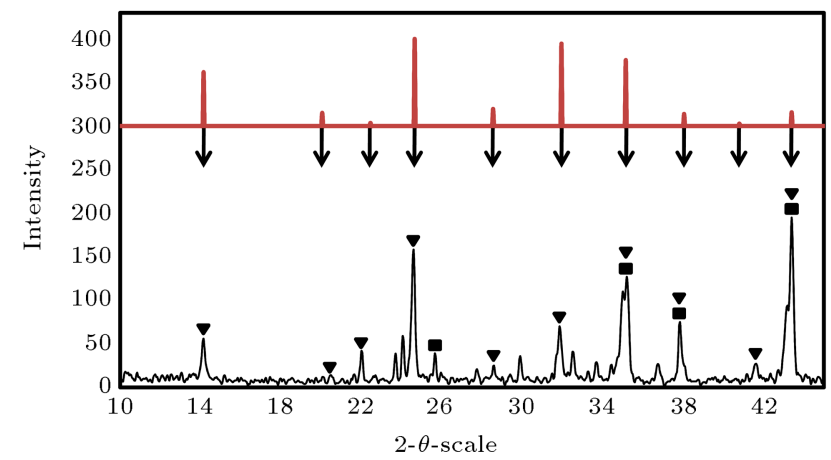

Figure 3. XRD pattern of $\alpha$-alumina ( $\mathbf{\square})$, and supported hydroxy sodalite membrane $(\mathbf{v})$.

conditions as those of the synthesized membrane. In Figure 3, the XRD pattern of synthesized membrane is shown. The XRD reflection of the synthesized membrane was correlated to the reference XRD of hydroxy sodalite [33]. Comparing the obtained XRD patterns indicates successful formation of hydroxy sodalite on the surface of support. As shown in Figure 3, some other extra peaks exist in XRD pattern, which are expected to be observed in sodalite membranes synthesized by in situ method [34]. But the intensity of the diffraction peaks of sodalite is intensified, which indicates that the sodalite has been dominant. The crystallite size was calculated around $41 \mathrm{~nm}$ using Scherrer formula, confirming nanometric microstructure of the synthesized membrane and resulting in high quality membrane, which will be investigated with more details using permeation experiments.

The SEM images of surface and cross section of the synthesized hydroxy sodalite membrane are depicted in Figure 4. As shown in the cross section image of the synthesized membrane, it has a uniform layer with thickness of around $20 \mu \mathrm{m}$, and the synthesized membrane is strongly bonded to the support. Also, the zeolite crystals are found to be well inter-grown and a continuous integrated membrane layer is formed on the surface of the home-made support (see surface SEM image in Figure 4).

\subsection{Gas permeation}

The synthesized membrane quality was evaluated by single gas permeation experiments using helium and $\mathrm{N}_{2}$ without removing water from its structure. Because the cavities of hydroxy sodalite are saturated with water during the synthesis procedure, the permeation of gas molecules through the membrane is impossible unless through defects. It was found that the membrane before drying step had no permeance for helium and nitrogen (the limit of the flow rate measurement was below $\left.\sim 10^{-11} \mathrm{~mol} \cdot \mathrm{m}^{-2} \cdot \mathrm{s}^{-1} \cdot \mathrm{Pa}^{-1}\right)$. This result together with the SEM images (Figure 4) confirms that the presence of defects in the prepared membrane microstructure is not considerable. Preparing another membrane with the same quality by the mentioned procedure approved the synthesis method. 

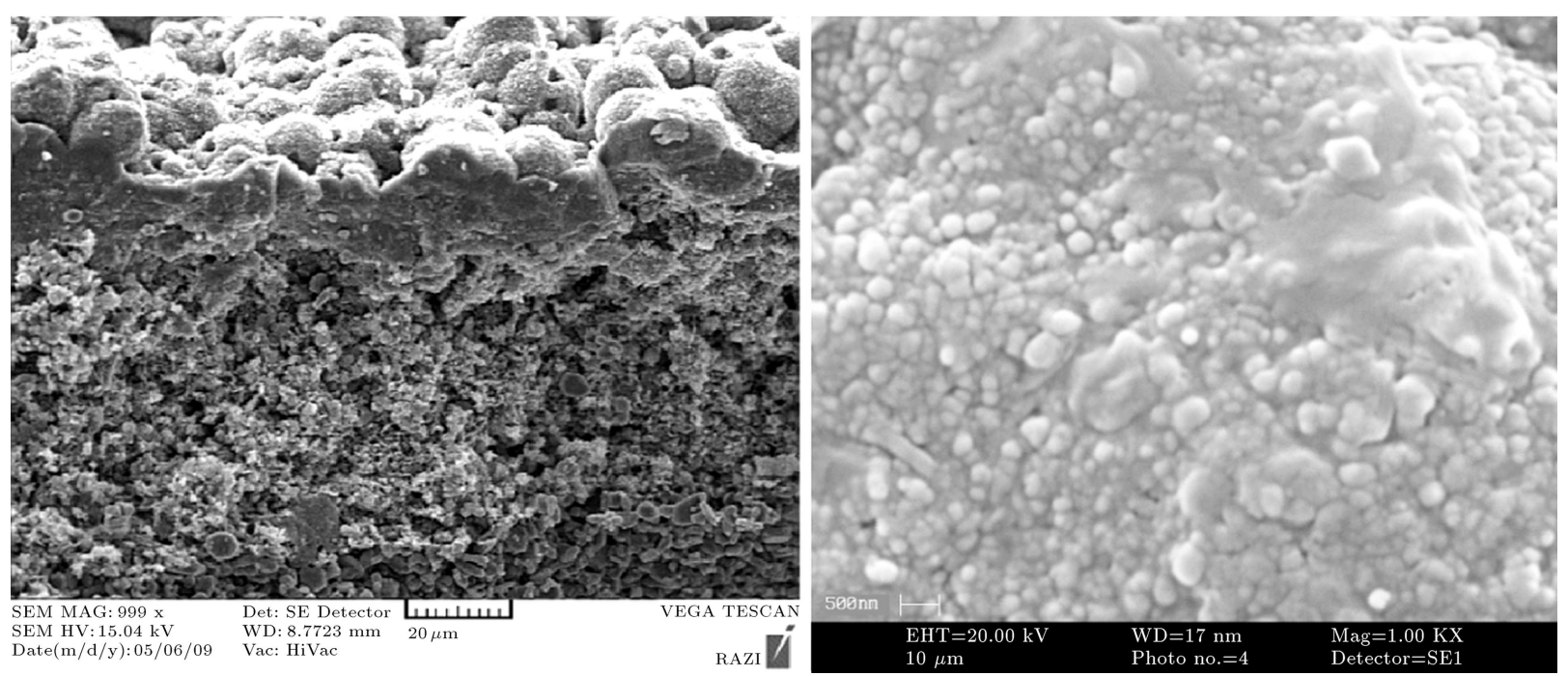

Figure 4. Top view (right) and cross-section (left) of the hydroxy sodalite membrane.

Single-gas permeation of different gases on zeolite membranes is frequently used to estimate the mechanism and, probably, the molecular sieving ability of a given membrane. So, the permeation test of helium, $\mathrm{N}_{2}, \mathrm{CO}_{2}$, and $\mathrm{CH}_{4}$ through the sodalite membrane was carried out to investigate the membrane performance in gas separation.

As mentioned, hydroxy sodalite has a threedimensional channel network. Thin films like hydroxy sodalite with cavity-containing regular structure indicate shape-selective diffusing mechanism. These films are permeable to small molecules and also to molecules that are short or narrow in at least one dimension. So that, shape selective behavior of hydroxy sodalite membrane can be based on transportation through intramolecular rather than intermolecular cavities.

In Figure 5(a), the pressure dependency of gases permeance at $85^{\circ} \mathrm{C}$ is shown. As a result, gases permeance has no strong pressure dependence. Also, the permeation results in Figure 5(b) show that permeance of all the examined gases decreases by increasing temperature. However, with a further increase in

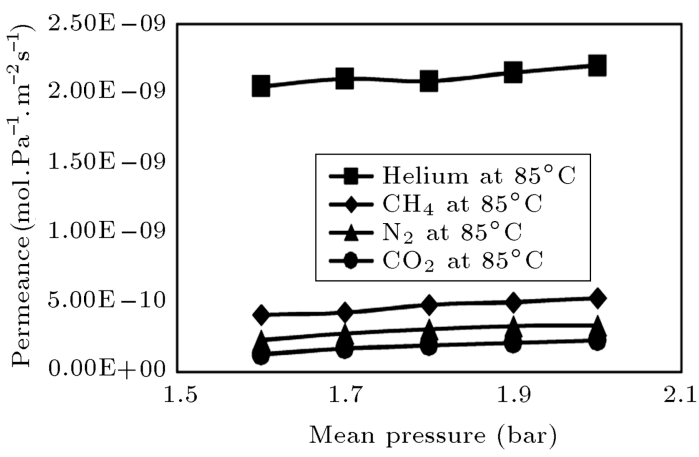

(a) temperature from 120 to $180^{\circ} \mathrm{C}$, the permeance of gases other than helium, is impossible to be measured. This behavior is due to the specific properties of different molecules and the inverse proportionality between the mean free path of molecules and temperature.

For more investigation on the performance of synthesized membrane, the ideal selectivity values for helium over other gases were determined as a function of mean pressure at $35^{\circ} \mathrm{C}$ (Figure 6). It is obvious that ideal selectivity of helium $/ \mathrm{CO}_{2}$ is more than those of the two others. The net mass transport of gases through the membrane has relationship with the polarity of gas molecules and it is controlled with both adsorption and diffusion mechanisms. As mentioned in the literature [35] for zeolites with six-membered rings (sodalite and $\mathrm{NaX}$ ), this kind of zeolite membranes has an electrostatic potential due to sodium ions located near the six-membered rings. It must be able to interact with polar molecules like $\mathrm{CO}_{2}$. The linear $\mathrm{CO}_{2}$ has a quadrupole moment with an arrangement of charges (-++-) [36]. Therefore, it should be able to form adsorption complexes with $\mathrm{Na}+$ ions within the

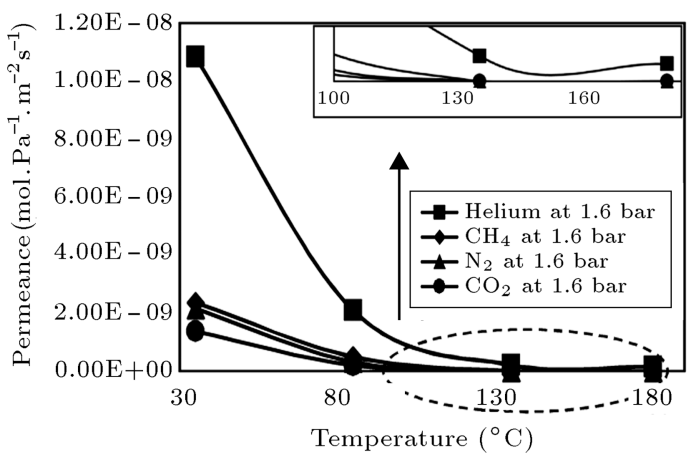

(b)

Figure 5. Permeance of helium, $\mathrm{CH}_{4}, \mathrm{~N}_{2}$, and $\mathrm{CO}_{2}$ versus (a) average pressure at $85^{\circ} \mathrm{C}$, and (b) temperature at 1.6 bar through the membrane. 


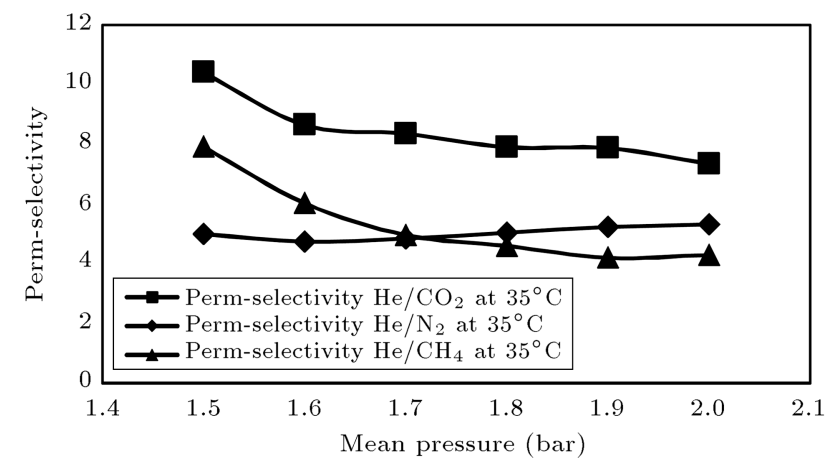

Figure 6. Perm-selectivity of helium over $\mathrm{CO}_{2}, \mathrm{~N}_{2}$, and $\mathrm{CH}_{4}$ versus average pressure (bar) at $35^{\circ} \mathrm{C}$.

membrane structure. Therefore, diffusing through the sodalite cage is difficult, and probably trapped in the different layer of zeolites. On the other hand, other gases like $\mathrm{N}_{2}$ neither have a dipole nor a quadrupole moment. So, nitrogen molecules can have higher permeance than $\mathrm{CO}_{2}$.

The same behavior can be observed in the ideal selectivity of helium $/ \mathrm{CO}_{2}$ compared to that of helium $/ \mathrm{CH}_{4}$ due to Non-polar structure of methane molecule. Also, comparing the ideal selectivity of helium $/ \mathrm{CH}_{4}$ with that of helium $/ \mathrm{N}_{2}$ indicates that the synthesized membrane is more perm-selective for helium $/ \mathrm{CH}_{4}$ than for helium/ $\mathrm{N}_{2}$ gas mixtures at low pressure. According to non-polar structure of methane and nitrogen molecules, the high ideal selectivity of helium $/ \mathrm{CH}_{4}$ at low pressures can be explained by kinetic diameter of them. But, by increasing the pressure, this trend is reserved, which can be due to spherical shape of methane molecule, leading to high permeance of $\mathrm{CH}_{4}$ at high pressures compared to nitrogen.

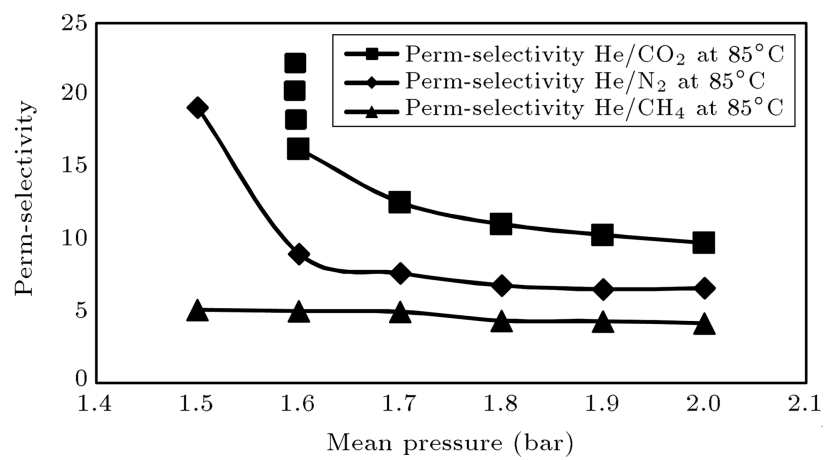

Figure 7. Perm-selectivity of helium over $\mathrm{CO}_{2}, \mathrm{~N}_{2}$, and $\mathrm{CH}_{4}$ versus average pressure (bar) at $85^{\circ} \mathrm{C}$.

In Figure 7 , the ideal selectivity of helium over other gases as a function of mean pressure at $85^{\circ} \mathrm{C}$ is shown. Non-measurable permeance of $\mathrm{CO}_{2}$ (very high selectivity of helium $/ \mathrm{CO}_{2}$ at low pressures) can be related to its quadrupole molecule structure. On the other hand, low ideal selectivity of helium $/ \mathrm{N}_{2}$ and helium $/ \mathrm{CH}_{4}$ is possible due to this fact that diatomic molecules, such as the spherocylindrical $\mathrm{N}_{2}$ and the tetrahedral $\mathrm{CH}_{4}$ molecule, all have specific degrees of rotational and/or translational freedom, which allow them to pass through the pores of many coordinated complexes, especially at high temperature.

Table 1 gives the permeance of all gases through the synthesized membrane at different temperatures and pressures, and Table 2 gives the perm-selectivity values of helium $/ \mathrm{CO}_{2}$, helium $/ \mathrm{CH}_{4}$, and helium $/ \mathrm{N}_{2}$ at different temperatures and pressures, which have been compared with Knudsen selectivity related to each of them. As a result of comparison, all the selectivity values were found to be higher than Knudsen selectivity.

Table 1. The permeance values of $\mathrm{He}, \mathrm{CH}_{4}, \mathrm{CO}_{2}$, and $\mathrm{N}_{2}$ at different temperatures and pressures.

\begin{tabular}{cccccccccc}
\hline $\mathbf{H e}$ & $\mathbf{3 5}{ }^{\circ} \mathbf{C}$ & $\mathbf{8 5} \mathbf{C}$ & $\mathbf{1 3 5}^{\circ} \mathbf{C}$ & $\mathbf{1 8 0}^{\circ} \mathbf{C}$ & $\mathbf{C H}_{\mathbf{4}}$ & $\mathbf{3 5}^{\circ} \mathbf{C}$ & $\mathbf{8 5} \mathbf{C}$ & $\mathbf{1 3 5}^{\circ} \mathbf{C}$ & $\mathbf{1 8 0}^{\circ} \mathbf{C}$ \\
\hline 1.5 & $9.98 \mathrm{E}-09$ & $2.00 \mathrm{E}-09$ & $1.84 \mathrm{E}-10$ & $1.14 \mathrm{E}-10$ & 1.5 & $1.26 \mathrm{E}-09$ & $3.94 \mathrm{E}-10$ & $\mathrm{IM}^{\mathrm{a}}$ & $\mathrm{IM}^{\mathrm{a}}$ \\
1.6 & $1.01 \mathrm{E}-08$ & $2.05 \mathrm{E}-09$ & $2.01 \mathrm{E}-10$ & $1.19 \mathrm{E}-10$ & 1.6 & $1.67 \mathrm{E}-09$ & $4.11 \mathrm{E}-10$ & $\mathrm{IM}^{\mathrm{a}}$ & $\mathrm{IM}^{\mathrm{a}}$ \\
1.7 & $1.04 \mathrm{E}-08$ & $2.10 \mathrm{E}-09$ & $2.06 \mathrm{E}-10$ & $1.34 \mathrm{E}-10$ & 1.7 & $2.09 \mathrm{E}-09$ & $4.27 \mathrm{E}-10$ & $\mathrm{IM}^{\mathrm{a}}$ & $\mathrm{IM}^{\mathrm{a}}$ \\
1.8 & $1.08 \mathrm{E}-08$ & $2.09 \mathrm{E}-09$ & $2.07 \mathrm{E}-10$ & $1.41 \mathrm{E}-10$ & 1.8 & $2.36 \mathrm{E}-09$ & $4.83 \mathrm{E}-10$ & $\mathrm{IM}^{\mathrm{a}}$ & $\mathrm{IM}^{\mathrm{a}}$ \\
1.9 & $1.13 \mathrm{E}-08$ & $2.15 \mathrm{E}-09$ & $2.16 \mathrm{E}-10$ & $1.45 \mathrm{E}-10$ & 1.9 & $2.69 \mathrm{E}-09$ & $5.01 \mathrm{E}-10$ & $\mathrm{IM}^{\mathrm{a}}$ & $\mathrm{IM}^{\mathrm{a}}$ \\
2 & $1.15 \mathrm{E}-08$ & $2.20 \mathrm{E}-09$ & $2.31 \mathrm{E}-10$ & $1.46 \mathrm{E}-10$ & 2 & $2.68 \mathrm{E}-09$ & $5.31 \mathrm{E}-10$ & $\mathrm{IM}^{\mathrm{a}}$ & $\mathrm{IM}^{\mathrm{a}}$ \\
\hline $\mathbf{C O}_{\mathbf{2}}$ & $\mathbf{3 5} \mathbf{C}$ & $\mathbf{8 5} \mathbf{C}$ & $\mathbf{1 3 5}^{\circ} \mathbf{C}$ & $\mathbf{1 8 0}^{\circ} \mathbf{C}$ & $\mathbf{N}_{\mathbf{2}}$ & $\mathbf{3 5} \mathbf{C}$ & $\mathbf{8 5} \mathbf{C}$ & $\mathbf{1 3 5}^{\circ} \mathbf{C}$ & $\mathbf{1 8 0}^{\circ} \mathbf{C}$ \\
\hline 1.5 & $9.60 \mathrm{E}-10$ & $\mathrm{IM}$ & $\mathrm{IM}$ & $\mathrm{IM}$ & 1.5 & $2.00 \mathrm{E}-09$ & $1.05 \mathrm{E}-10$ & $\mathrm{IM}^{\mathrm{a}}$ & $\mathrm{IM}^{\mathrm{a}}$ \\
1.6 & $1.16 \mathrm{E}-09$ & $1.26 \mathrm{E}-10$ & $\mathrm{IM}^{\mathrm{a}}$ & $\mathrm{IM}$ & 1.6 & $2.12 \mathrm{E}-09$ & $2.28 \mathrm{E}-10$ & $\mathrm{IM}^{\mathrm{a}}$ & $\mathrm{IM}^{\mathrm{a}}$ \\
1.7 & $1.24 \mathrm{E}-09$ & $1.68 \mathrm{E}-10$ & $\mathrm{IM}^{\mathrm{a}}$ & $\mathrm{IM}^{\mathrm{a}}$ & 1.7 & $2.14 \mathrm{E}-09$ & $2.77 \mathrm{E}-10$ & $\mathrm{IM}^{\mathrm{a}}$ & $\mathrm{IM}^{\mathrm{a}}$ \\
1.8 & $1.37 \mathrm{E}-09$ & $1.89 \mathrm{E}-10$ & $\mathrm{IM}^{\mathrm{a}}$ & $\mathrm{IM}^{\mathrm{a}}$ & 1.8 & $2.15 \mathrm{E}-09$ & $3.08 \mathrm{E}-10$ & $\mathrm{IM}^{\mathrm{a}}$ & $\mathrm{IM}^{\mathrm{a}}$ \\
1.9 & $1.43 \mathrm{E}-09$ & $2.09 \mathrm{E}-10$ & $\mathrm{IM}^{\mathrm{a}}$ & $\mathrm{IM}^{\mathrm{a}}$ & 1.9 & $2.16 \mathrm{E}-09$ & $3.31 \mathrm{E}-10$ & $\mathrm{IM}^{\mathrm{a}}$ & $\mathrm{IM}^{\mathrm{a}}$ \\
2 & $1.56 \mathrm{E}-09$ & $2.26 \mathrm{E}-10$ & $\mathrm{IM}^{\mathrm{a}}$ & $\mathrm{IM}^{\mathrm{a}}$ & 2 & $2.16 \mathrm{E}-09$ & $3.35 \mathrm{E}-10$ & $\mathrm{IM}^{\mathrm{a}}$ & $\mathrm{IM}^{\mathrm{a}}$ \\
\hline
\end{tabular}

a: IM: Too low permeance made the measurement impossible. 
Table 2. The perm-selectivity values of $\mathrm{He} / \mathrm{CO}_{2}, \mathrm{He} / \mathrm{CH}_{4}$, and $\mathrm{He} / \mathrm{N}_{2}$ at different temperatures and pressures.

\begin{tabular}{|c|c|c|c|c|c|c|c|c|}
\hline $\mathrm{Helium} / \mathrm{CO}_{2}$ & $35^{\circ} \mathrm{C}$ & $85^{\circ} \mathrm{C}$ & Helium/ $\mathrm{CH}_{4}$ & $35^{\circ} \mathrm{C}$ & $85^{\circ} \mathrm{C}$ & Helium/ $\mathbf{N}_{2}$ & $35^{\circ} \mathrm{C}$ & $85^{\circ} \mathrm{C}$ \\
\hline 1.5 & 10.40 & - & 1.5 & 7.91 & 5.08 & 1.5 & 4.99 & 19.14 \\
\hline 1.6 & 8.64 & 16.26 & 1.6 & 6.02 & 4.99 & 1.6 & 4.74 & 8.98 \\
\hline 1.7 & 8.35 & 12.53 & 1.7 & 4.96 & 4.93 & 1.7 & 4.84 & 7.61 \\
\hline 1.8 & 7.90 & 11.04 & 1.8 & 4.59 & 4.33 & 1.8 & 5.04 & 6.78 \\
\hline 1.9 & 7.87 & 10.28 & 1.9 & 4.19 & 4.30 & 1.9 & 5.23 & 6.51 \\
\hline 2 & 7.35 & 9.74 & 2 & 4.29 & 4.14 & 2 & 5.31 & 6.58 \\
\hline $\mathrm{Kn}^{\mathrm{a}}$ selectivity & 3.32 & & $\mathrm{Kn}^{\mathrm{a}}$ selectivity & 2.00 & & $\mathrm{Kn}^{\mathrm{a}}$ selectivity & 2.65 & \\
\hline
\end{tabular}

a: Kn: Knudsen

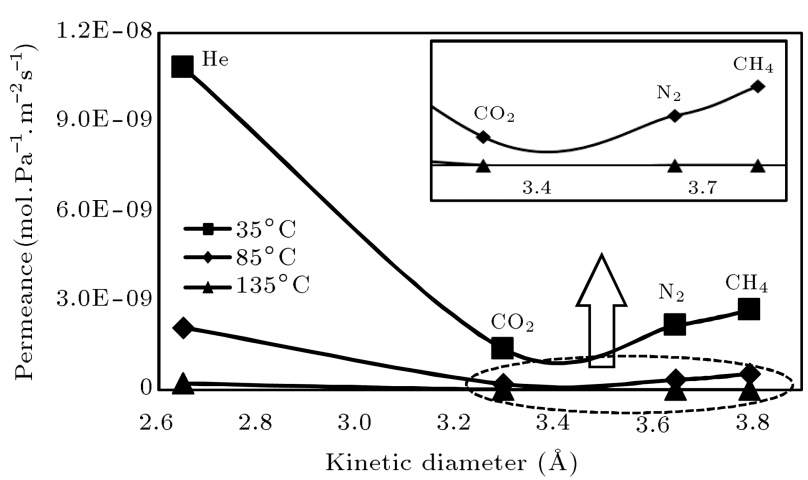

Figure 8. Permeance of gas molecules through the membrane versus their kinetic diameter at 35,85 , and $135^{\circ} \mathrm{C}$.

To demonstrate the dominant mechanism in the gases permeation through the synthesized membrane, permeance was plotted against the kinetic diameter at different temperatures (Figure 8). As it is obvious, at high temperatures $\left(>85^{\circ} \mathrm{C}\right)$, the permeance of large gas molecules $\left(\mathrm{N}_{2}, \mathrm{CO}_{2}\right.$ and $\left.\mathrm{CH}_{4}\right)$ is not measurable. This trend confirms that the synthesized membrane has high potential in the separation of helium from $\mathrm{N}_{2}$, $\mathrm{CO}_{2}$, and $\mathrm{CH}_{4}$ at high temperatures.

\section{Conclusion}

Hydroxy sodalite membrane with high performance in gas separation has been prepared on tubular $\alpha$ $\mathrm{Al}_{2} \mathrm{O}_{3}$ support. Selective sodalite membrane layer was obtained by the repeated synthesis procedure. Single gas permeation measurements of helium, $\mathrm{CO}_{2}, \mathrm{~N}_{2}$, and $\mathrm{CH}_{4}$ were carried out as a function of temperature and feed pressure. Permeance of gases through the membrane decreased with an increase in temperature due to the inverse proportionality between mean free path of gas molecules and temperature. The permselectivity values obtained for helium over gases at low temperature were higher than Knudsen diffusion ratio, which confirmed that hydroxy sodalite membrane with good integrity had been obtained. Above $85^{\circ} \mathrm{C}$, an activated type of gas transport through the membrane took place which showed very high selectivity towards helium in the range of $135-180^{\circ} \mathrm{C}$. Different permselectivity values of gases are possible due to different molecule sizes, shapes, and energetic interactions of the gases with heteropolar inner surface of sodalite. $\mathrm{CO}_{2}$ with a quadrupolar molecule is able to interact with the inner surface of sodalite, so it has individual permeation behavior in comparison with other gases. The best separation factor with acceptable permeance for helium $/ \mathrm{CO}_{2}$, helium $/ \mathrm{N}_{2}$, and helium $/ \mathrm{CH}_{4}$ was measured $\sim 16.5, \sim 8.8$ and $\sim 5$ at $85^{\circ} \mathrm{C}$, respectively. Nevertheless, for achieving high perm-selectivity values, high temperature operation $\left(>85^{\circ} \mathrm{C}\right)$ is recommended, because at high temperatures $\left(135^{\circ} \mathrm{C}\right)$, the ability of the membrane to separate helium from gases is attributed mainly to the size and shape of molecules.

\section{Acknowledgments}

The authors wish to thank Sahand University of Technology (SUT) for the financial support of this work. Also, they thank co-workers and technical staff in the Chemical Engineering Department, Institute of Nanostructure Materials Research Center of SUT, for their help during various stages of this work.

\section{References}

1. Schreiber, W.G., Morbach, A.E., Stavngaard, T., Gast, K.K., Herweling, A., Søgaard, L.V., Windirsch, M., Schmiedeskamp, J., Heussel, C.P. and Kauczor, H.U. "Assessment of lung microstructure with magnetic resonance imaging of hyperpolarized Helium", Resp. Physiol. Neurobi., 148, pp. 23-42 (2005).

2. Belyakov, V.V., Krakovskii, B.D., Popov, O.M., Step, G.Kh. and Udut, V.N. "Low-capacity hydrogen liquefier with a helium cycle", Chem. Petrol. Eng., 38, pp. 3-4 (2002).

3. Ichard, M., Hansen, O.R., Middha, P. and Willoughby, D. "CFD computations of liquid hydrogen releases", Int. J. Hydrogen Energ., 37, pp. 17380-18389 (2012).

4. Hu, W., Wu, X., Li, Zh. and Yang, J. "Helium separation via porous silicene based ultimate membrane", $J$. R. Soc. Chem., 5, pp. 9062-9066 (2013). 
5. Yao, M.S., Wang, R.P., Liu, Z.Y., He, X.D. and Li, J. "The helium purification system of the HTR-10", Nucl. Eng. Des., 218, pp. 163-167 (2002).

6. Pakizeh, M., Omidkhah, M.R. and Zarringhalam, A. "Study of mass transfer through new templated silica membranes prepared by gel method", Int. J. Hydrogen Energ., 32, pp. 2032-2042 (2007).

7. Mourgues, A. and Sanchez, J. "Theoretical considerations about a membrane process for helium purification in multichannel monoliths for high temperature nuclear reactors", Nucl. Eng. Des., 247, pp. 88-97 (2012).

8. Chung, T.S., Chan, S.S., Wang, R., Lu, Z. and He, C. "Characterization of permeability and sorption in Matrimid/C60 mixed matrix membranes", J. Membrane Sci., 211, pp. 91-99 (2003).

9. Gantzel, P.K. and Merten, U. "Gas separations with high-flux cellulose acetate membranes", Ind. Eng. Chem. Proc., DD 9, pp. 331-333 (1970).

10. Min, K.E. and Paul, D.R. "Tacticity on permeation properties of poly(methylethacrylate)", J. Polym. Sci. Pol. Phys., 26, pp. 1021-1033 (1988).

11. Robeson, L.M. "Correlation of separation factor versus permeability for polymeric membranes", J. Membrane Sci., 62, pp. 165-85 (1991).

12. Chiou, J.S. and Paul, D.R. "Gas permeation in a dry Nafion membrane", Ind. Eng. Chem. Res., 27, pp. 2161-2164 (1988)

13. Kim, T.H., Koros W.J. and Husk, G.R. "Advanced gas separation membrane materials: rigid aromatic polyimides", Separ. Sci. Technol., 23, pp. 1611-1126 (1988).

14. Peterson, E.S. and Stone, M.L. "Helium separation properties of phosphazene polymer membranes", $J$. Membrane Sci., 86, pp. 57-65 (1994).

15. Agrawal, J.P. and Sourirajan, S. "Helium separation by cellulose acetate membranes", J. Appl. Polym. Sci., 13, pp. 1065-1068 (1969).

16. Vareltzis, P., Kikkinides, E.S. and Georgiadis, M.C. "On the optimization of gas separation processes using zeolite membranes", Chem. Eng. Res. Des., 81(5), pp. 525-536 (2003).

17. Vospernik, M., Pintar, A., Bercic, G., Batista, J. and Levec, J. "Potentials of ceramic membranes as catalytic three-phase reactors", Chem. Eng. Res. Des., 82(A5), pp. 659-666 (2004).

18. Arkharov, I.A., Bondarenko, V.L. and Mikhailov, A.V. "Obtaining neon from a neon-helium mixture on a quartz glass membrane", Chem. Petrol. Eng., 38, pp. 5-6 (2002).

19. Favvas, E.P., Kouvelos, E.P., Romanos, G.E., Pilatos, G.I., Mitropoulos, A.Ch. and Kanellopoulos, N.K. "Characterization of highly selective microporous carbon hollow fiber membranes prepared from a commercial co-polyimide precursor", J. Porous Mater., 15, pp. 625- 633 (2008).
20. Favvas, E.P., Heliopoulos, N.S., Papageorgiou, S.K., Mitropoulos, A.Ch., Apantaidakis, G.C. and Kanellopoulos, N.K. "Helium and hydrogen selective carbon hollow fiber membranes: the effect of pyrolysis isothermal time", Separ. Purif. Technol., 142, pp. 176-181 (2015).

21. Kafrouni, W., Rouessac, V., Julbe, A. and Durand, J. "Synthesis of PECVD a-SiCXNY:H membranes as molecular sieves for small gas separation", J. Membrane Sci, 329, pp. 130-137 (2009).

22. Schrier, J. "Helium separation using porous graphene membranes", J. Phys. Chem. Lett., 1, pp. 2284-2287 (2010).

23. Li, H., Song, Z., Zhang, X., Huang, Y., Li, S., Mao, Y., Ploehn, H.J., Bao, Y. and Yu, M. "Ultrathin, molecular-sieving graphene oxide membranes for selective hydrogen separation", Science, 342, pp. 95-98 (2013).

24. Hasegawa, Y., Kusakabe, K. and Morooka, Sh. "Effect of temperature on the gas permeation properties of NaY-type zeolite formed on the inner surface of a porous support tube", Chem. Eng. Sci., 56, pp. 42734281 (2001).

25. Masuda, T., Asanuma, T., Shouji, M., Mukai, Sh.R., Kawase, M. and Hashimoto, K. "Methanol to olefins using ZSM-5 zeolite catalyst membrane reactor", Chem. Eng. Sci., 58, pp. 649-656 (2003).

26. Yu, M., Noble, R.D. and Falconer, J.L. "Zeolite membranes: Microstructure characterization and permeation mechanisms", Acc. Chem. Res., 44, pp. 11961206 (2011).

27. Khajavi, Sh., Jansen, J.C. and Kapteijn, F. "Production of ultra-pure water by desalination of seawater using a hydroxy sodalite membrane", J. Membrane Sci., 356, pp. 52-57 (2010b).

28. Julbe, A., Motuzas, J., Cazevielle, F., Volle, G. and Guizard, C. "Synthesis of sodalite $/ \alpha \mathrm{Al}_{2} \mathrm{O}_{3}$ composite membranes by microwave heating", Sep. Purif. Technol., 32, pp. 139-149 (2003).

29. Khajavi, Sh., Sartipi, S., Gascon, J., Jansen, J.C. and Kapteijn, F. "Thermostability of hydroxy sodalite in view of membrane applications", Micropor. Mesopor. Mat., 132, pp. 510-517 (2010c).

30. Babaluo, A.A. and Kokabi, M. "Manufacture of porous support systems of membranes by in-situ polymerization", Iran Polym. J., 15(3), pp. 187-194 (2002).

31. Khajavi, Sh., Jansen, J.C. and Kapteijn, F. "Preparation and performance of H-SOD membranes: a new synthesis procedure and absolute water separation. From Zeolites to Porous MOF Materials", The 40th Anniversary of International Zeolite Conference, pp. 1028-1035 (2007).

32. Khajavi, Sh., Jansen, J.C. and Kapteijn, F. "Performance of hydroxy sodalite membranes as absolute water selective materials under acidic and basic conditions", J. Membrane Sci., 356, pp. 1-6 (2010a). 
33. Treacy, M.M.J. and Higgins, J.B., Collection of Simulated XRD Powder Patterns for Zeolites, 4th Edn., Elsevier, New York, USA (2001).

34. Yampolskii, Y., Pinnau, I. and Freeman, B., Materials Science of Membranes for Gas and Vapor Separation, John Wiley \& Sons, Ltd., England (2006).

35. Weh, K., Noack, M., Sieber, I. and Caro, J. "Permeation of single gases and gas mixtures through faujasite-type molecular sieve membranes", Micropor. Mesopor. Mat., 54, pp. 27-36 (2002).

36. Hemalatha, P., Bhagiyalakshmi, M., Ganesh, M., Palanichamy, M., Murugesan, V. and Jang, H.T. "Role of ceria in $\mathrm{CO}_{2}$ adsorption on NaZSM-5 synthesized using rice husk ash", J. Ind. Eng. Chem., 18, pp. 260265 (2012).

\section{Biographies}

Mohammad Javad Vaezi received the BSc degree in Chemical Engineering from Sahand University of Technology, Tabriz, Iran, in 2010, and MSc degree in Chemical Engineering from Sahand University of Technology in 2012. He is currently a PhD student of Chemical Engineering at Sahand University of Technology. His research interests are in the general area of separation science, especially gas separation by membrane process, including hydrogen and natural gas purification. He has published over 7 research articles on related subjects. In the last years, he presented different courses on chemical engineering.

Now he continues his research at Sahand University of Technology as PhD student in the field of Zeolite membrane for natural gas purification.

Yaser Bayat received the BSc degree in Chemical Engineering from Guilan University, Rasht, Iran, in 2009, and MSc degree in Chemical Engineering from Sahand University of Technology in 2011. His research interests are in the general area of separation science, especially gas separation by membrane process, including natural gas sweetening and purification. $\mathrm{He}$ has published over 9 research articles of his research activities. He is currently commercial manager at Petro-Taha Company, Tehran, Iran.

Ali Akbar Babalou, after graduating from high school in 1992, continued his education in Chemicalpetrochemical Engineering at Sahand University of
Technology (SUT). Then, he continued his education and graduated with PhD degree in 2004.

After that, Dr. Babaluo continued his education and research-based activities at SUT as Assistant Professor. In the last decade, he presented different specialized courses in BSc, MSc, and $\mathrm{PhD}$ degrees, and his research and technical-based activities have strongly been continued of which some of the most important activities are:

- More than 80 journal papers;

- More than 150 national and international conference papers;

- Research projects: 13 completed and 4 in running;

- Supervising more than $55 \mathrm{MSc}$ and PhD theses;

- 16 national patents (2 patents have scientific certificate);

- 10 awards as selected researcher at different levels.

Dr. Babaluo has also done other different scientific activities such as: publishing a journal; creating research center and incubator; writing book and book chapter; working as an editorial board member of two research journals; presenting scientific comments, corrections, and corrigendum on published articles. Now, he continues his viable activities at Sahand University of Technology as a Full-Professor.

Sirous Shafiei received the BSc degree in Chemical Engineering from Abadan Institute of Technology, Iran, in 1988, and MSc and PhD degrees in Chemical Engineering from Shiraz University, Iran, in 1994 and Toulouse institute of Technology, France, in 2002, respectively.

He is currently an Associate Professor of Chemical Engineering at Sahand University of Technology. He is also a Professional Member of Iranian Chemical Engineers Society. His research interests are in the general area of modeling, simulation, and optimization of chemical processes, environment engineering. He has published over 10 research articles on related subjects. In the last decade, he presented different specialized courses.

He was awarded as the best teacher in academic year 2008-2009 and, now, he continues his research activities at Sahand University of Technology as an Associate Professor. 